Article

\title{
The Development of Scientific Activity in Russian Universities
}

\author{
Marina Vasiljeva ${ }^{1}{ }^{*}$, Vadim Ponkratov ${ }^{2}$, Tatyana Volkova ${ }^{3}$, Saida Khairova ${ }^{4}$, Natalya Nikitina ${ }^{5}$, \\ Olesya Dudnik ${ }^{6}$, Maria Alimova ${ }^{7}$, Nikolay Kuznetsov ${ }^{8}$ and Izabella Elyakova ${ }^{9}$
}

1 Autonomous Non-Profit Organization “Publishing House Scientific Review” (Nauchnoe Obozrenie), 9 Sukharevskiy M. lane, bld. 1, 127051 Moscow, Russia

2 Financial Policy Center of the Public Finance Department, Financial University under the Government of the Russian Federation, Leningradsky Prospekt 49, 125993 Moscow, Russia; ponkratovvadim@yandex.ru

3 Department of Economics and Production Organization, Bauman Moscow State Technical University, 105005 Moscow, Russia; Tatyana.I.Volkova@yandex.ru

4 Institute of Master and Graduate Studies, Siberian State Automobile and Highway University (SibADI), Prospekt Mira, 5, 644080 Omsk, Russia; saida.khairova@yandex.ru

5 Research Institute of Perspective Directions and Technologies, Russian State Social University, 129226 Moscow, Russia; Natalya.I.Nikitina@yandex.ru

6 Departament of Pediatric Dentistry and Orthodontics, I.M. Sechenov First Moscow State Medical University (Sechenov University), Bol'shaya Pirogovskaya Ulitsa, 19c1, 119146 Moscow, Russia; Olesya.V.Dudnik@yandex.ru

7 Russian Language Department №4, RUDN University, 117198 Moscow, Russia; maria.alimova@inbox.ru

8 Research Institute of Digital Transformation Management, State University of Management, 99 Ryazansky Av., 109542 Moscow, Russia; n1ck.kuznetsov@yandex.ru

9 Department of Economics and Finance, North-Eastern Federal University, 677000 Yakutsk, Russia; izabella.elyakova@yandex.ru

* Correspondence: marina.vasiljeva2017@gmail.com

Received: 11 August 2020; Accepted: 8 October 2020; Published: 12 October 2020

\begin{abstract}
The aim of this article was to develop scientific activity in Russian universities. Using the survey method, a sample of quantitative indicators of research output for the years 2011-2019 was formed. The respondents were comprised of 934 lecturers from 13 universities in Russia with different work experience, academic degrees, and indicators of scientific activity. The main components method was used to study the structure of scientific activity productivity indicators. Using the method of additive convolution, a five-factor integral model of the structure of scientific activity of a teacher was formed to evaluate the individual and collective productivity of scientific activity. The factor values and the integral indicator of scientific activity output were calculated, showing that the individual growth rates of the young lecturers' output exceeded the growth rates of the older lecturers. Destructive factors relating to the scientific activity output of the lecturers and researchers in Russian universities (divided into two groups of young scientists and senior scientists) were determined and systematized based on the level of dominant influence. The features of the influence of the factor of emotional burnout on the scientific productivity of university teachers were revealed.
\end{abstract}

Keywords: higher education; publication productivity; researcher; Russia; university; scientific performance

\section{Introduction}

The innovation system, with its close relationship with science, industry, and society, is the basis for the efficient social and economic development of society. In this system, the needs of innovation 
development determine and stimulate the most important directions of scientific activity [1-3]. There are currently no mechanisms to ensure the efficient interaction between science, industry, and society in Russia [4]. Therefore, it is the higher education system and the universities that may become points of growth for the country's innovation development.

The functional specifics of universities do allow for the efficient integration of personnel training, research, and the commercialization of the results of intellectual activity [5]. As stated in "A Contribution to the Horizon 2020 Mid-Term Review" [6], the future of universities is related to their scientific activity development and achievements. Modern universities are platforms for strategic breakthroughs in countries' social and economic development as they are centers for generating innovative solutions and influencing the industrial sector, social projects, and spatial development.

In recent years, there have been significant institutional and regulatory changes that have transformed approaches to the development of higher education. University 3.0 vision (science, education, and business) implies that ambitious objectives in the area of science have been set. By 2024, the goal is to ensure that Russia is among the five leading countries in the world engaged in research and development in the areas identified as priorities for scientific and technological development [7]. Therefore, the integration of education and scientific activities through the development of higher education and major scientific and educational centers should be a priority.

Scientific work is one of the most important activities of the faculty and postgraduate students of any higher education institution [8]. It should be noted that the number of higher education institutions in Russia engaged in research and development is steadily growing. However, in the 1990s, the number of higher education institutions (HEIs) engaged in research and development was less than 10\%; by 2018, the figure had grown to almost 100\% [9]. The growth of HEIs' share in the system of organizations engaged in research and development is primarily due to the introduction of a system for evaluating their efficiency, which includes indicators of research activities. Thus, since 2013, the national demands placed on universities have included services not only for the implementation of programs of higher professional education, but also for supporting the generation of research papers [9]. However, it should be noted that in 2018, the number of scientists in the country was 682,500 , which is $7.3 \%$ less than in 2010 and 3.6\% less than in 2017 [10]. This is explained by the mass outflow of Russian scientists to foreign countries. In addition, there is the sensitive subject of the aging of scientific personnel. The average age of Russian scientists is far above 50. One in three are older than the retirement age [11].

The decrease in the number of scientists in HEIs is accompanied by a rather low level of scientific performance. Since 2001, the number of patent applications for inventions filed by Russian applicants at home and abroad has increased by $39 \%$. Nevertheless, Russia accounts for about $1 \%$ of the world's applications, or holds 10th place in the global ranking. The level of citation of Russian scientists' papers, which reflects the global scientific community's demand for published research, has been growing in recent years, yet in almost all fields of science, it is still below the world average [12]. Dissatisfaction with the various aspects of scientific activity is one of the main factors hindering successful scientific work.

Policymakers at HEIs have long been concerned with both achieving maximum research output and the contextual impact on this output [13-15]. Knowing why some faculty members are more productive than others and what factors influence their research output is therefore essential for developing efficient research output improvement $[14,16,17]$. Although researchers have long sought explanations for faculty scientific performance using various factors [13-16,18-20], contextual factors are believed to better explain the output than psychological and individual characteristics [17].

However, it is impossible to discuss the factors of scientific output without understanding what that output is and how it can be measured. Depending on which output indicators are used, different results can be obtained regarding the relationship of the output to different factors. This paper focuses on how different factors influence researcher output and seeks to develop a methodological approach to the assessment of the individual and collective scientific output of lecturers in Russian 
universities. Other research goals include determining a rationale and systematizing the destructive factors of scientific output.

\section{Literature Review}

In the context of research organizations, bibliometricians have become accustomed to defining research output or productivity as the number of publications per researcher, distinguishing it from the impact that they measure by citations [21]. As early as 1926, Alfred J. Lotka dwelled on the number of publications in his milestone work [22], where he presented what it is now known as Lotka's Law. Unfortunately, from an economic standpoint (output and productivity are concepts created within the economic theory), such a definition makes little sense. It would be acceptable only if all publications had the same value or impact, but that is certainly not the case [22]. Research productivity is a production process in which the inputs consist of human, tangible (scientific instruments, materials, etc.) and intangible (accumulated knowledge, social networks, economic rents, etc.) resources, and the output, the new knowledge, has a complex character of both tangible (publications, patents, conference presentations, databases, etc.) and intangible nature (tacit knowledge, consulting activity, etc.) [21].

The assessment of the output is the mechanism that the scientific community uses to certify and control the production of knowledge. Quantitative indicators are not just scientific products [23]; they also serve as tools in evaluating, regulating, and drawing up policy [24]. They were first applied to the evaluation of productivity in the late 19th century [25] and have often been linked to research funding. Bibliometric indicators are currently one of the key tools in assessing the scientific capacity of individuals or institutions [26]. One of the main indices is the impact factor, formulated by Eugene Garfield in 1952 to ascertain the quality of science journals, but there are other, lesser known indicators, such as the immediacy index, prestige factor, and usable factor [27].

The quantitative approach came hand-in-hand with the development of bibliometrics in productivity evaluation. Bibliometrics is a product of the progressive convergence of statistics, sociology, and information technology in the evaluation of researchers, groups, and institutions. More precisely, it entails procedures that contribute to productivity evaluation based on the number of publications, the prestige of the publishing journals, and citation patterns [28]. This approach has gained increasing ground because it affords distilled, factual information on the dynamics of the scientific community. While bibliometrics may produce serious distortions when used in isolation, its application in assessing scientific activity output has fueled much excitement and transformed scientific articles into a central factor. They centered on the notion of authorship, as expressed through publication in specialized journals. On the one hand, this is an overly narrow view of the functions of science, as suggested by John D. Bernal [29], in that it takes into account nothing but the final product of scientific activity, while excluding gray literature, that is, the transfer of tacit knowledge, which is the everyday routine of science. On the other hand, this approach is a manifestation of the Matthew Effect, as formulated by Robert K. Merton [30], where the eminent researchers tend to get more credit than their less well known colleagues and therefore enjoy more prestige, access to funding, and visibility. Therefore, in this study, we considered the factors that influence the scientific activity output and that are taken into account directly in its assessment.

Researchers attempt to explain the variation in faculty research performance by individual psychological factors, including superior intellectual ability, a strong motivation, personality traits, and background characteristics. Researchers describe numerous factors that determine the efficiency of scientific activity. Most of them tend to identify three groups, namely individual, organizational and institutional factors $[17,31,32]$. As a rule, the impact of factors is in direct proportion to the scientific activity output; with the acquisition of pedagogical and scientific experience, the indicators of scientific performance are expected to increase [33]. Nevertheless, it should be noted that the practice of scientific and pedagogical activity witnesses the decrease in lecturer interest in scientific activity that can be explained by professional difficulties, financial dissatisfaction, emotional burnout, etc. $[33,34]$. Therefore, special attention should be paid to the factors of dissatisfaction with various 
aspects of scientific activity that hinder productivity in science. According to Frederick Herzberg's two-factor theory of motivation [35], factors influencing job satisfaction are divided into two groups. Salary rate, working hours, social and hygienic conditions, workplace organization, relations with colleagues, relations with the boss, technical equipment, the possibility of solving social and domestic problems belong to the first group of factors, which are termed external or hygiene factors. Resources contribute to a productive research career, which is why high-quality institutions typically have access to funding, time for faculty research, competent assistants, stimulating colleagues, and easy access to information [36]. In addition, it is believed that the in the emerging economies, the financing of science is crucial for the development of scientific productivity $[37,38]$. The second group includes the diversity of work, the demand to solve new problems, self-sufficiency in work, the correspondence of work to personal abilities, and the possibility of promotion. These ones were termed internal factors or motivators.

One of the most controversial aspects in the research of factors that influence scientific activity output is the varying peculiarities associated with the scientists' age group. Some researchers point out the differences in the motivators for young and senior lecturers [39-41]. Others refute this point of view [42]. As already noted, with the accumulating pedagogical and scientific experience, indicators of scientific performance have to increase. However, we tend to believe that for young and senior lecturers, such dynamics may differ significantly in the direction and pace of change, conditioned by the influence of factors determining the efficiency of their scientific activity. Therefore, we formulated a number of hypotheses characterizing the changes in the indicators of the efficiency of lecturers' scientific activity, and the factors affecting this efficiency (Table 1).

Table 1. The paper's hypotheses.

\begin{tabular}{cc}
\hline Hypothesis Statement & Designation \\
\hline $\begin{array}{c}\text { The dynamics of individual performance indicators of scientific activity } \\
\text { has a bottom-up character. }\end{array}$ & H1 \\
$\begin{array}{c}\text { There are statistically significant differences in the scientific performance } \\
\text { development dynamics of young and senior lecturers. } \\
\text { Young lecturers are characterized by a decline in overall scientific } \\
\text { performance due to staff outflows. }\end{array}$ & H2 \\
$\begin{array}{c}\text { Professional difficulties and financial dissatisfaction are the reason why } \\
\text { young lecturers are less interested in scientific activities. }\end{array}$ & H3 \\
$\begin{array}{c}\text { The main reason for the reduced interest in scientific activities of senior } \\
\text { lecturers is emotional burnout. }\end{array}$ & H4 \\
\hline
\end{tabular}

It should be noted that, alongside education, scientific work is one of the most important activities in universities, whereas it is the only activity undertaken in research organizations. Consequently, we distinguished between the factors determining the efficiency of scientific activity in HEIs and scientific organizations." These aspects have been taken into account in carrying out the present research.

\section{Methods and Materials}

\subsection{Qualitative Indicators for Evaluating the Scientific Productivity of Universities}

The list of criteria for the productivity of the lecturer scientific activity used in this study is based on a number of papers $[43,44]$ with the possibility of their quantitative assessment. The quantitative indicators were used because the statistical proof of the suggested hypotheses is required. The indicators were considered criteria for the productivity of scientific activity (Table 2). 
Table 2. The indicators of the productivity of scientific activity in the higher education system.

\begin{tabular}{|c|c|}
\hline Indicators & Designation \\
\hline Doctor of Sciences degree * & $\mathrm{X} 1$ \\
\hline Candidate of Sciences degree * & $\mathrm{X} 2$ \\
\hline International awards for scientific work & X3 \\
\hline Number of publications in Scopus and WoS journals (over the last 5 years) & $\mathrm{X} 4$ \\
\hline $\begin{array}{c}\text { Number of publications in journals that are included in other international scientometric } \\
\text { bases (over the last } 5 \text { years) }\end{array}$ & X5 \\
\hline Number of papers published abroad (over the last 5 years) ${ }^{* *}$ & $\mathrm{X} 6$ \\
\hline Number of published monographs (over the last 5 years) & $\mathrm{X} 7$ \\
\hline Number of published textbooks and manuals (over the last 5 years) & $\mathrm{X} 8$ \\
\hline Number of monographs, textbooks and manuals published abroad (over the last 5 years) & X9 \\
\hline Number of international internships (over the last 5 years) & $\mathrm{X} 10$ \\
\hline Number of presentations at international conferences (over the last 5 years) & $\mathrm{X} 11$ \\
\hline $\begin{array}{c}\text { Number of Candidate of Sciences theses defended under one's academic advising (over the } \\
\text { last } 5 \text { years) }\end{array}$ & $\mathrm{X} 12$ \\
\hline $\begin{array}{c}\text { Number Doctor of Sciences theses defended under one's academic advising (over the last } \\
5 \text { years) }\end{array}$ & $\mathrm{X} 13$ \\
\hline Intellectual property items (patents for inventions and models) (over the last 5 years) & $\mathrm{X} 14$ \\
\hline $\begin{array}{l}\text { Note: }{ }^{*} \text { Doctor and Candidate of Sciences are academic degrees that are awarded based on the res } \\
\text { defense. Doctor of Sciences is the highest (after Candidate of Sciences) academic degree. Candidate } \\
\text { the academic degree corresponding to the PhD degree in Western countries. It is the lowest, in compa } \\
\text { Doctor of Sciences, academic degree. }{ }^{* *} \text { Foreign articles mean articles published in all, except Russi } \\
\text { collections that are not indexed in the scientometric databases, such as Scopus and WoS. }\end{array}$ & $\begin{array}{l}\text { lts of public } \\
\text { f Sciences is } \\
\text { son with the } \\
\text {, journals or }\end{array}$ \\
\hline
\end{tabular}

Among the indicators are the Doctor of Sciences degree (indicator X1) and the Candidate of Sciences degrees (indicator X2). Despite the small number of manifestations of the X1 indicator among respondents, it has a high discriminating ability when dividing scientists into two young and senior ones. The $\mathrm{X} 3$ indicator characterizes the international activity of a scientist, their productivity in terms of the international recognition of their scientific results.

Indicators $\mathrm{X} 4-\mathrm{X} 6$ assess the publication activity. The $\mathrm{X} 4$ indicator does not imply any specification regarding the journal's quartile. This includes all publications in Scopus and WoS over the last 5 years.

Under current conditions, the importance of publications in journals, which are indexed in Scopus and WoS scientometric bases is increasing, which is confirmed by the National Project of the Russian Federation "Science" [45], the Orders of the Ministry of Science and Higher Education of the Russian Federation" [46] and [47]. According to these regulatory legal acts, when planning target indicators for standards of scientific activity and assessing their implementation, articles published in Russian journals are not taken into account (with the exception of those indexed in the scientometric databases, such as Scopus and WoS). In this regard, the indicator of the number of publications in Russian journals and in this study was not used.

The number of publications in other bases according to the Order [47] was not taken into account, but in this study, the indicators X5 and X6 have been introduced with the purpose of the deeper examination of publication activity.

In addition to the publication of papers, the scientific activity output was manifested in the number of published monographs (indicator X7), textbooks, and manuals (X8). The X9 indicator highlights the number of monographs, textbooks, and manuals published abroad. The number of international internships (X10) is an indicator that describes how a scientist boosts their own output by drawing on international experience, the development of new methods, mechanisms, and opportunities for research. The number of presentations at the international conferences (X11) on the one hand is the result of scientific activity, while on the other hand, it is the possibility of advanced training. Indicators X12 and X13 characterize the scientist's output as an academic advisor. The intellectual property items (X14), along with indicators $\mathrm{X} 4-\mathrm{X} 9$, X11, are a form of expressing the tangible results of scientific activity. 
The research does not use such an indicator as the number of carried out research, research and development and the funding received due to the fact that this type of research usually involves a large number of scientists, so it is problematic to assess the individual contribution of each in the research. Accordingly, this indicator is not sufficiently informative to assess the output of an individual scientist. At the same time, individual research and development results are partially manifested through indicators $\mathrm{X} 3-\mathrm{X} 9, \mathrm{X} 11, \mathrm{X} 14$, which are forms of presenting research results.

The adequacy of the proposed list of indicators of scientific activity output is estimated by the cumulative percentage of dispersion conducted on the basis of the specified indicators of factor analysis, which is $91.76 \%$ (Table 3). The percentage of factorization (dispersion), which exceeds $80 \%$ [48], indicates the representativeness of the proposed system of indicators-criteria of scientific activity productivity at the level of universities.

Table 3. Factors defining the performance indicators dynamics for scientific activity.

\begin{tabular}{cc}
\hline No. & Factor \\
\hline 1 & Lack of opportunity for professional growth \\
2 & Dissatisfaction with the level of payment for the results of scientific activity \\
3 & The lack of creative development opportunities \\
4 & Psychological dissatisfaction with scientific activity \\
5 & Lack of opportunities for self-expression in the process of scientific activity \\
6 & Lack of appropriate material, technical, software and information support for \\
& scientific activity \\
\hline 7 & Dissatisfaction with the organization of the educational process \\
\hline 8 & Another reason \\
\hline
\end{tabular}

\subsection{Determination of the Structure and Significance of Factors of Productivity of Scientific Activity}

We formulated a model to assess the output of scientific activity using factor analysis and expert analysis methods. The model involves the assessment of individual (at the level of a single lecturer) and collective (the whole sample of lecturers) output indicators in the context of the constituent elements (factors) on the basis of integral assessment.

The process of making the model implies a number of phases:

i. Determining the structure of factors (the indicators of scientific activity output). To study the structure of indicators, the principal components analysis was used with the purpose of reducing the data and proving the adequacy of the statistical base (the topic coverage via X1-X14 indicators). The Kaiser criterion was used to determine the number of factors. The scope of factors was obtained using factor analysis and principal components analysis based on a survey using the Statistica 10.0 software.

ii. Assessment of the factors of the scientific activity output. Data reduction made it possible to single out factors that describe the productivity of lecturer scientific activity. The factor values (Formula (1)) for them are determined using the normalization of indicators $\left(X_{n j}\right)$ and the obtained values of the coefficients of linear regression equations $\left(k_{i}\right)$. This approach to data processing allowed avoiding the multicollinearity of indicators without a loss of information. The values of the factors $\left(F_{i}\right)$ were obtained according to the results of factor analysis in the program Statistica 10.0:

$$
F_{i}=\sum k_{j i} \times X_{n j}
$$

where $F_{i}$ is the $i$-th factor of lecturer scientific activity output; $k_{j i}$ the coefficient of linear regression equations that describes the relative significance of the $j$-th indicator within the $i$-th factor; $X_{n j}$ the normalized value of the $j$-th indicator; $i$ the factor serial number; $j$ the indicator serial number; and $n$ the number of indicators of lecturer scientific activity output 
iii. Determination of factor significance coefficients for the integral model. For this purpose, factor analysis and expert evaluation were used. Factor analysis enabled the acquisition of the percentage of dispersion of factors $\left(d_{i}\right)$, characterizing the informative value of the selected factors when describing the lecturer's scientific activity output. The use of dispersion percentages as significance coefficients ensured the objectivity of evaluation results. However, this approach to building an integral indicator only took into account the informative value of factors without their relative significance, when a relatively higher percentage of dispersion can be attributed to a more numerical representation of a certain factor (a large number of variables that form the factor). In this connection, to nullify this disadvantage, it was proposed to supplement the results of the factor analysis with expert evaluation. The expert group included 40 representatives of the Ministry of Science and Higher Education of the Russian Federation, all members of the departments of state scientific and technical policy, the certification of scientific and pedagogical workers, scientific and technical programs, the co-ordination of activities of scientific organizations, and innovations and prospective studies. The competence of experts is ensured by their professional specialization, work experience, and reputation. For this purpose, the competence coefficients for each $k$-th expert were calculated as a ratio of the sum of expert group assessments (except for the $k$-th expert whose competence is assessed) to the number of experts (except for $k$-th expert). The estimations have been made in the following way: " 0 " is when the expert considers the $k$-th expert to be incompetent and does not see the expediency of including them in the expert group; " 1 " is when the expert has expressed the need to include the $k$-th expert in the group. The calculated competence coefficients are 0.9-1, which indicates the competence of the formed expert group. Competence of the experts, the total number of the expert group (40 persons), and a high degree of coherence of the opinions under conditions of anonymity, are estimated on the basis of the concordance coefficient, providing the representativeness and reliability of the evaluation results. The correlation coefficient was 0.86 .

The experts were asked to evaluate the significance of factors F1 to F5, identified as a result of factor analysis in describing the lecturer publication activity on a 10-point scale. The significance increases as the score increases from 1 to 10 . The coefficients of significance of the factors based on the results of expert evaluation were calculated by the following Formula (2):

$$
\begin{gathered}
p_{i k}=\left[b_{i k} / \sum b_{i k}\right] \times\left[\sum e_{k} /(m-1)\right], \\
p_{i}=\sum p_{i k},
\end{gathered}
$$

with $p_{i}$ being an expert evaluation of the $i$-th factor significance coefficient; $b_{i k}$ being a score given by the $k$-th expert with regard to $i$-th factor significance $(b=\overline{1,10}) ; \sum b_{i k}$ being a sum of scores given by the $k$-th expert with regard to all factors; $t$ being a number of factors; $\sum e_{k /}(m-1)$ being a coefficient of the $k$-th expert competence; $\sum e_{k}$ being a sum of binary scores $(e=0 \cap 1$, “ 0 " - the expert considers the $\mathrm{k}$-th expert to be incompetent and does not see the expediency of including them in the expert group; " 1 "- the expert has expressed the need to include the $k$-th expert in the group), given by the expert group ( $m-1$ experts) with regard to $k$-th expert competence; $m$ being the number of experts in the expert group.

The significance coefficients calculated using Formula (2) are the expert group's average relative indicators of the factor significance weighted on the expert's competence. These coefficients characterize the direct significance of the factors and also take into account the expert's competence: an expert with the highest competence has a greater influence on the resulting assessment. The disadvantage of this approach in determining the significance is subjectivity (although the criteria of ensuring the representativeness of the expert evaluation are fulfilled). To solve this problem, a combination of the 
results of the factor (dispersion coefficients) and expert (expert evaluation of coefficients of significance) methods of analysis is proposed for the third variant (Formula (3)):

$$
\begin{gathered}
w_{i(1)}=\left[\left(d_{i}+p_{i}\right) / 2\right] / \sum\left[\left(d_{i}+p_{i}\right) / 2\right], \\
w_{i(2)}=\left(d_{i} \times p_{i}\right) / \sum\left(d_{i} \times p_{i}\right), \\
w_{i(3)}=\left(R_{p i}+R_{d i}\right) / \sum\left(R_{p i}+R_{d i}\right),
\end{gathered}
$$

where $w_{i}$ is the $i$-th factor significance coefficient; $d_{i}$ the $i$-th factor fractional dispersion; $p_{i}$ an expert estimation of the $i$-th factor significance coefficient, calculated using Formula (2); $R_{p i}$ the $i$-th factor rank in terms of the $p_{i}$ indicator; $R_{d i}$ the $i$-th factor rank in terms of the $d_{i}$ indicator. The higher the factor significance, the higher the rank, $R_{p i}, R_{d i}=1$, for the less significant factor. $w_{i(1)}$ presupposes the calculation of significance coefficients from a position where the effects of variance and expert estimation have equal strength to the calculation of the integral indicator $(I)$; with $w_{i(2)}$, the adjustment of expert estimation on the percentage of variance is being made and $w_{i(3)}$ is calculated on the basis of rating scores, and not the relative ones (as in the cases of $w_{i(1)}$ and $w_{i(2)}$ ).

\subsection{Determination of the Quantitative Values of the Factors of Scientific Productivity and the Reasons for Their Decline}

Indicator values (Table 2) were obtained on the basis of survey results, which implied a binary evaluation of indicators X1-X3 and quantitative evaluation of indicators X4-X14. The answer option "Yes" for indicators $\mathrm{X} 1-\mathrm{X} 3$ is transformed into value " 1 ", the answer option "No" is transformed into value " 0 ".

The survey was conducted between 2011 and 2019 with a 2 year time interval. The participants of the survey were the same respondents, namely 934 lecturers from 13 Russian universities with different work experience, academic degrees and indicators of scientific activity. Here is the list of the HEIs: South Urals State Agrarian University, N.I. Pirogov Russian National Research Medical University, Ufa State Petroleum Technical University, Tolyatti State University, Omsk State Technical University, Moscow Finance and Law University, Moscow Technical University of Communications and Informatics, Moscow State Institute of Culture, Russian State Sociological University, V.I. Surikov Moscow State Institute of Academic Art, S.G. Stroganov Moscow State Art and Industry Academy, Moscow State Medical and Dental University, Academy of Labor and Social Relations. The universities are of different specializations in order to ensure the versatility of scientific research results. The survey was carried out remotely by means of e-mail. In order to ensure the representativeness of the results, lecturers from Russia's leading universities, which have additional factors to stimulate the scientific activity, such as additional funding, were not involved in the survey. The survey is voluntary, which is in line with the principles of research ethics.

The number of respondents (934), which exceeds 273 , is sufficient to describe the behavior of a large general population, i.e., to determine the factors of scientific activity efficiency in the Russian higher education system. An amount of 273 people is the minimum required number of respondents, which ensures the representativeness of the sample based on a confidence level of $90 \%$, a confidence interval of $\pm 5 \%$ and the size of the general population $>30$ people.

The number of respondents (934) is also sufficient for a factor analysis. According to the requirements for factor analysis, the number of observations (in this case respondents) should be $(2 n+1)$ times higher than the number of variables (indicators X1-X14) [48]. The representativeness of the indicators, the sufficiency and versatility of the sample ensured the adequacy and statistical significance of the research results.

The hypothesis that there are differences in the dynamics of scientific activity indicators of young and senior lecturers allowed dividing the sample of respondents into two categories-young lecturers (aged up to 39 years.) and senior lecturers (aged 40 years and older)—that comprised 422 and 512 people, respectively. The "Nauka" National Project was used as a basis for dividing lecturers into 
young and old [45]. According to this project, young lecturers are those under 39 years of age inclusive, and old lecturers are those 40 years of age or older [45].

The efficiency of the scientific activity of young and old lecturers has been studied separately because, as evidenced by the Literature Review, there are different opinions on the factors that affect the efficiency of the scientific activity of these two categories of lecturers, which was confirmed by the research.

The second part of the questionnaire is aimed at studying the factors that determine the dynamics of scientific activity output indicators and implies the examination of the emotional burnout (in terms of Boyko's method [49]), as well as financial and other reasons for decreasing interest in scientific activity in lecturers. Respondents were asked to choose one factor from the list, which is a decisive deterrent in their formation and development as scientists (Table 3)

The completeness of the proposed list of the potentially constraining factors is evidenced by the survey results. All respondents indicated factors $1-7$ as constraining factors, without using the option of choosing another reason.

The factors characterizing the quality of the management at the level of the state (education system), university, faculty were not considered in this article. These factors are basic and affect the effectiveness of scientific activity by means of other factors, such as: the possibility of professional growth, self-expression, creative development; satisfaction with the organization of the educational process, the level of payment, the existing material, technical and other base, psychological satisfaction with scientific work (factors 1-7 of the proposed list).

Effective management should be aimed at realizing these opportunities and increasing employee satisfaction. The factors considered in the article are, on the one hand, indicators of the effectiveness of management from the perspective of teaching staff and on the other hand, reflect the personal factor of the workers themselves.

\subsection{An Integral Model for Assessing the Productivity of Scientific Activity}

Using three calculation options is designed to get the most accurate assessment of the scientific activity output:

i. Calculation of the integral indicator of the scientific activity output (I). An additive convolution of factors $\left(F_{i}\right)$ was used to calculate the integral indicator of the scientific activity output as adjusted for factor significance coefficients $\left(w_{i}\right)$ :

$$
I=\sum\left(w_{i} \times F_{i}\right)
$$

ii. Choosing the best option for calculating significance factors $\left(w_{i(1)} \cap w_{i(2)} \cap w_{i(3)}\right)$ from the standpoint of ensuring the maximum accuracy of the results of integrated assessment. The accuracy of the assessment was estimated using pair correlation coefficients between the value of the integral indicator of the scientific activity output $(I)$ and X1-X14 indicators values, which were used as a basis for calculating the factors and the integral indicator $\left(r_{I, X 1}, r_{I, X 2}, \ldots\right.$, $\left.r_{I, X n}\right)$. The highest average value of the correlation coefficient indicates the highest accuracy of the assessment of the corresponding option. This criterion for choosing the best option was used as the integral indicator of the scientific activity output should most accurately reflect the values and dynamics of its individual indicators. The indicator $r^{\prime}$ is informative only if indicators $r_{I, X 1}, r_{I, X 2}, \ldots, r_{I, X n}$ are at the same level, and there are no significant differences between their values. That is when the high value of the average indicator is not provided by the high value of one or more indicators, and the influence of others is not taken into account. For that purpose, the hypothesis (H0) was tested, which shows that the values of the correlation coefficients $r_{I, X 1}, r_{I, X 2}, \ldots, r_{I, X n}$ do not differ 
In order to approximate the law of the distribution of correlation coefficients to normal, Fisher $z$-transformation was used. The obtained variable $z$, which is distributed in accordance with the normal law, allowed calculating the standard deviation $\sigma_{z}$. To test the hypothesis $\mathrm{H} 0$, the following formula was used:

$$
U=\left(z_{1}-z_{2}\right) / \sqrt{ }\left[1 /\left(h_{1}-3\right)+1 /\left(h_{2}-3\right)\right],
$$

where $z_{1}, z_{2}$ are the results of transforming a pair of correlation coefficients $\left(r_{I, X 1}-r_{I, X 2}, r_{I, X 1}-r_{I, X 3}\right.$, $r_{I, X 2}-r_{I, X 3}$, etc.), and $h_{1}, h_{2}$ are the correspondent sample sizes.

The choice of the optimal option for calculating the factor significance coefficient was carried out according to criterion $r^{\prime}=\max$ (with $r^{\prime}$ being the arithmetic mean of correlation coefficients $r_{I, X 1}, r_{I, X 2}$, $\left.\ldots, r_{I, X n}\right)$, provided that the hypothesis $\mathrm{H} 0$ is tested.

Based on this criterion, the model for evaluating the productivity of scientific activity takes the following form:

$$
I=\sum\left[d_{i} \times p_{i} \times F_{i} / \sum\left(d_{i} \times p_{i}\right)\right]
$$

In addition to calculating factors and an integral indicator for the entire sample (in order to identify patterns across the sample), the proposed integrated model involves the calculation of similar indicators per 100 respondents (in order to identify individual patterns).

To test the hypotheses $\mathrm{H} 1-\mathrm{H} 3$ put forward in the study regarding the patterns of the development of the scientific activity output (Table 1), model (6) was used; to test the hypotheses H4 and H5, questionnaires based on the method of studying emotional burnout [49] were used.

\section{Results}

A factor analysis of survey responses by young and senior lecturers during the period 2011-2019 $(N=4,163)$ produced the structure of scientific activity output shown in Table 4 . The number of observations corresponds to the total number of processed questionnaires during the period 2011-2019 (934 for 2011, 872 for 2013, 850 for 2015, 764 for 2017, and 743 for 2019).

Table 4. Factors boosting scientific activities output in Russian universities.

\begin{tabular}{lcc}
\hline \multicolumn{1}{c}{ Factor } & Indicators & Dispersion, \% \\
\hline F1-Scientific, methodological, and tutorial activity & $\mathrm{X} 7, \mathrm{X} 8, \mathrm{X} 9, \mathrm{X} 14$ & 23.07 \\
F2-Scientific recognition & $\mathrm{X} 1, \mathrm{X} 2, \mathrm{X} 3$ & 22.11 \\
F3-Publication activity & $\mathrm{X} 4, \mathrm{X} 5, \mathrm{X6}$ & 21.08 \\
F4-International scientific activity & $\mathrm{X} 10, \mathrm{X} 11$ & 13.84 \\
F5-Academic advising & $\mathrm{X} 12, \mathrm{X} 13$ & 11.66 \\
\hline
\end{tabular}

The factor of scientific, methodological, and tutorial activity explained $23.07 \%$ of the dispersion of indicators of scientific activity; this factor was based on the indicators of the number of monographs, textbooks, and manuals that were published and the number of intellectual property items that were produced. Academic degrees and international awards explained $22.11 \%$ of the dispersion. Publication activity explained a further $21.08 \%$ of the dispersion, where the indicators of this factor included the number of publications in the journals listed in Scopus and WoS, as well as other international scientometric databases, and the number of articles published abroad. Finally, the factors of international scientific activity and advising explained $13.84 \%$ and $11.66 \%$ of the dispersion, respectively. Taken together, these factors explained $91.76 \%$ of the total dispersion of indicators of scientific activity. This high percentage of factorization indicates the completeness of the factor analysis.

The priority of factors was distributed in the following sequence: F3 had the highest relative significance indicator, 0.25 , as calculated with by the formula (2), while F2 significance was $0.24, F 1$ and F4 significance were both 0.18 , and F5 significance was 0.15 (Table 5). 
Table 5. Factor significance in estimating the scientific activity output.

\begin{tabular}{cccc}
\hline Factor $\left(F_{i}\right)$ & Dispersion $\left(\boldsymbol{d}_{\boldsymbol{i}}\right)$ & $\begin{array}{c}\text { Expert Estimation of the } \\
\text { Significance Coefficient }\left(\boldsymbol{p}_{\boldsymbol{i}}\right)\end{array}$ & Significance Coefficient $\left(w_{\boldsymbol{i}}\right)$ \\
\hline F1 & 0.23 & 0.18 & 0.22 \\
F2 & 0.22 & 0.24 & 0.28 \\
F3 & 0.21 & 0.25 & 0.28 \\
F4 & 0.14 & 0.18 & 0.13 \\
F5 & 0.12 & 0.15 & 0.09 \\
\hline
\end{tabular}

The second variant of formula (3) was used to calculate the significance coefficient because it returned the highest average correlation coefficient (0.89) (the first variant of the formula returned 0.76 and the third variant returned 0.64 ). These results show that scientific activity output can be most precisely estimated if corrections are made to the significance of factors for the dispersion of the factor. Indicator ranks $d i$ and $p i$ are less precise. The second variant of the formula did not confirm the hypothesis $\mathrm{H} 0$ that the correlation coefficient values $r_{I, X 1}, r_{I, X 2}, \ldots, r_{I, X n}$ do not differ. Calculated values were within the range $[1.24 ; 1.43]$ with the tabular value 1.96 for the significance level $\alpha=0.05$.

Table 6 presents the dynamics of the F1-F5 factor values in the context of the age structure of lecturers and the integral indicator as calculated with formula (5).

Table 6. Dynamics of the factor values and integral indicator of scientific activity output in Russian universities.

\begin{tabular}{|c|c|c|c|c|c|c|c|c|c|c|c|c|}
\hline \multirow{4}{*}{ Factor } & \multicolumn{12}{|c|}{ Factor Values (for the Whole Sample) } \\
\hline & \multicolumn{6}{|c|}{ Young Lecturers } & \multicolumn{6}{|c|}{ Senior Lecturers } \\
\hline & 2011 & 2013 & 2015 & 2017 & 2019 & \multirow[b]{2}{*}{ Dynamics } & 2011 & 2013 & 2015 & 2017 & 2019 & \multirow[b]{2}{*}{ Dynamics } \\
\hline & $\begin{array}{c}N^{*}= \\
422\end{array}$ & $\begin{array}{l}N= \\
367\end{array}$ & $\begin{array}{l}N= \\
349\end{array}$ & $\begin{array}{l}N= \\
271\end{array}$ & $\begin{array}{l}N= \\
256\end{array}$ & & $\begin{array}{l}N= \\
512\end{array}$ & $\begin{array}{l}N= \\
505\end{array}$ & $\begin{array}{l}N= \\
501\end{array}$ & $\begin{array}{l}N= \\
493\end{array}$ & $\begin{array}{l}N= \\
487\end{array}$ & \\
\hline $\mathrm{F} 1$ & 1.03 & 0.94 & 1.01 & 0.92 & 1.11 & $\boldsymbol{a}+\mathbf{E}$ & 2.37 & 2.46 & 2.6 & 2.69 & 2.72 & - \\
\hline F2 & 2.09 & 1.87 & 2.19 & 2.03 & 2.37 & & 2.97 & 3.04 & 3.29 & 3.33 & 3.67 & \\
\hline F3 & 1.65 & 1.55 & 1.59 & 1.43 & 2.04 & & 1.87 & 1.89 & 2.06 & 2.18 & 2.3 & \\
\hline $\mathrm{F} 4$ & 1.1 & 1.06 & 1.37 & 1.2 & 1.49 & - & 1.19 & 1.24 & 1.4 & 1.55 & 1.59 & \\
\hline F5 & 0 & 0 & 0 & 0 & 0 & - & 0.87 & 0.99 & 1.19 & 1.27 & 1.42 & \\
\hline \multirow[t]{4}{*}{$\begin{array}{l}\text { Integral } \\
\text { productivity } \\
\text { indicator }\end{array}$} & 1.41 & 1.29 & 1.45 & 1.32 & 1.66 & & 2.10 & 2.16 & 2.35 & 2.44 & 2.59 & \\
\hline & \multicolumn{12}{|c|}{ Factor Values (for 100 Respondents) } \\
\hline & \multicolumn{6}{|c|}{ Young Lecturers } & \multicolumn{6}{|c|}{ Senior Lecturers } \\
\hline & 2011 & 2013 & 2015 & 2017 & 2019 & Dynamics & 2011 & 2013 & 2015 & 2017 & 2019 & Dynamics \\
\hline F1 & 0.24 & 0.26 & 0.29 & 0.34 & 0.43 & --- & 0.46 & 0.49 & 0.52 & 0.55 & 0.56 & \\
\hline F2 & 0.50 & 0.51 & 0.63 & 0.75 & 0.93 & -- & 0.58 & 0.60 & 0.66 & 0.68 & 0.75 & -- \\
\hline F3 & 0.39 & 0.42 & 0.46 & 0.53 & 0.80 & & 0.37 & 0.37 & 0.41 & 0.44 & 0.47 & -- \\
\hline F4 & 0.26 & 0.29 & 0.39 & 0.44 & 0.58 & $--\boldsymbol{\square} \mathbf{\square}$ & 0.23 & 0.25 & 0.28 & 0.31 & 0.33 & $--m$ \\
\hline F5 & 0 & 0 & 0 & 0 & 0 & - & 0.17 & 0.20 & 0.24 & 0.26 & 0.29 & $-0 \square$ \\
\hline $\begin{array}{l}\text { Integral } \\
\text { productivity } \\
\text { indicator }\end{array}$ & 0.33 & 0.35 & 0.42 & 0.49 & 0.65 & -- & 0.41 & 0.43 & 0.47 & 0.50 & 0.53 & \\
\hline
\end{tabular}


The survey results show that there are differences in the dynamics of development of scientific activity output indicators for young and senior lecturers. This is confirmed by the dynamics of the factors in Table 5 and Student's $t$-criterion for the samples corresponding to two age groups. The empirical value of the Student's $t$-criterion was within the range [3.48;7.21], as the tabular value with $d f \rightarrow \infty$ is 1.96. Empirical values of Student's $t$-criterion that are higher than the tabular ones confirm the $\mathrm{H} 2$ hypothesis.

During the period being studied, a decrease in the values of all factors and the integral efficiency indicator for junior lecturers in 2013 and 2017 was observed. For lecturers of the older age category, upward dynamics of scientific efficiency indicators was observed throughout the whole period.

The analysis of indicators of an individual respondent showed an increase in scientific output over the course of scientific and pedagogical activities, which is manifested in an increase in the number of publications, academic degrees and intensification of international activities. This is evidenced by an increase in the values of all factors for 100 respondents of all age categories, which confirms the H1 hypothesis. Individual growth rates of scientific productivity in junior lecturers exceed the growth rates of efficiency in the senior group. Therefore, it can be argued that the reason for the decline in the overall indicators for the scientific output of junior lecturers is outflow, which confirms the H3 hypothesis. Out of 422 junior lecturers surveyed in 2011, 256 remained in work at the university in 2019. Among the junior lecturers, $39.34 \%$ had changed profession. The survey revealed that the majority of junior lecturers who changed profession were in the second or fourth year of their scientific-pedagogical activity (43.7\% and 52.4\%, respectively). For this reason, the questionnaire included a question relating to "Scientific and pedagogical experience", and it was clarified that all respondents were university lecturers at the time of the survey. Thus, the main reason for the reduction in the overall output of junior scientists was identified as the outflow.

Among the senior lecturers, the outflow is not so significant (an average of $1.24 \%$ over 2 years, $4.88 \%$ during the 2011-2019 period), which did not have a negative impact on overall scientific productivity. Nor is there a consistent dependence on the number of lecturers leaving the university.

The results obtained by studying emotional burnout allowed us to reveal the following trends relating to junior lecturers as of 2019. Among them, 33\% reached the "Stress Phase", with dominant features such as "Self-dissatisfaction" and "Feeling trapped in a cage"; $67 \%$ of respondents did not exhibit any emotional burnout. Among the junior lecturers who changed profession, only $8 \%$ had reached the "Stress Phase" in the previous year of the study. This indicates that emotional burnout cannot be the reason for a reduced interest in science among junior lecturers, and for their dismissal.

Among senior lecturers in 2019, only 17\% had no signs of emotional burnout; $29 \%$ had reached the "Stress Phase" with the dominant feature of "Self-dissatisfaction"; $45 \%$ had reached the "Resistance Phase", with the dominant feature of "Stepping outside the comfort zone"; 9\% had reached the "Exhaustion Phase"; with dominant features of "Emotional loss" and "Emotional detachment" (Table 7).

In a survey conducted in 2011, "emotional detachment" was characteristic of seven respondents who, by the time of the next survey, had stopped working in the education sector; in 2013, it was characteristic of six respondents, out of which four of them were dismissed; in 2015, it was characteristic of seven respondents, all of whom had been dismissed; in 2017, it was characteristic of five respondents who had all changed their occupation. It was noted that out of the 25 people who were at the stage of "emotional detachment" in this study spanning 2011-2017, 23 did not continue to work in the education sector. Therefore, the results obtained confirmed the H5 hypothesis that the main reason for the decrease in interest in participating in the scientific activities of senior lecturers was emotional burnout. Decrease in the interest in scientific activity was considered to be due to the fact that the individual performance indicators of scientific activity for young and senior lecturers increase, while the overall decline in scientific productivity (or slowdown in the rate of efficiency increase) in the sample was due to a decrease in the number of lecturers. 
Table 7. Phases of emotional burnout among the senior lecturers in Russian universities.

\begin{tabular}{cccccc}
\hline Phases of Emotional Burnout & \multicolumn{5}{c}{ Manifestation of Phases in Years, \% } \\
\cline { 2 - 6 } & $\mathbf{2 0 1 1}$ & $\mathbf{2 0 1 3}$ & $\mathbf{2 0 1 5}$ & $\mathbf{2 0 1 7}$ & $\mathbf{2 0 1 9}$ \\
\hline $\begin{array}{c}\text { Stress, with the dominant symptom of } \\
\text { dissatisfaction with oneself }\end{array}$ & 20 & 22 & 23 & 28 & 29 \\
$\begin{array}{c}\text { Stress, with the dominant symptom of } \\
\text { feeling oneself in a cage }\end{array}$ & 11 & 13 & 6 & - & - \\
$\begin{array}{c}\text { Stress, with the dominant symptoms of } \\
\text { anxiety and depression }\end{array}$ & 5 & 2 & 4 & 4 & - \\
$\begin{array}{c}\text { Resistance, with the dominant symptom of } \\
\text { expansion of the sphere of saving emotions }\end{array}$ & 18 & 22 & 31 & 36 & 45 \\
$\begin{array}{c}\text { Resistance, with the dominant symptom of } \\
\text { reduction of professional duties }\end{array}$ & 3 & 3 & - & - & - \\
$\begin{array}{c}\text { Exhaustion, with the dominant symptom of } \\
\text { emotional deficit }\end{array}$ & 1 & 5 & 6 & 5 & 8 \\
$\begin{array}{c}\text { Exhaustion, with the dominant symptom of } \\
\text { emotional detachment }\end{array}$ & 1 & 1 & 1 & 1 & 1 \\
$\quad$ No signs of emotional burnout & 41 & 32 & 29 & 26 & 17 \\
\hline
\end{tabular}

According to the results of the study, it was determined that for the majority of senior lecturers, the main reasons for the decline in scientific productivity were psychological dissatisfaction, lack of opportunities for self-expression, and the absence of creative development, which correlate with the results of the assessment of emotional burnout. For young scientists, hypothesis H4 was confirmed, according to which the professional difficulties that correspond to dissatisfaction with the organization regarding the educational process $(36.1 \%)$ and financial dissatisfaction $(31.3 \%)$ are the chief reasons for the decrease in interest in scientific activity.

The results that showcase the constraining factors for the development of scientific activity output are shown in Figure 1.

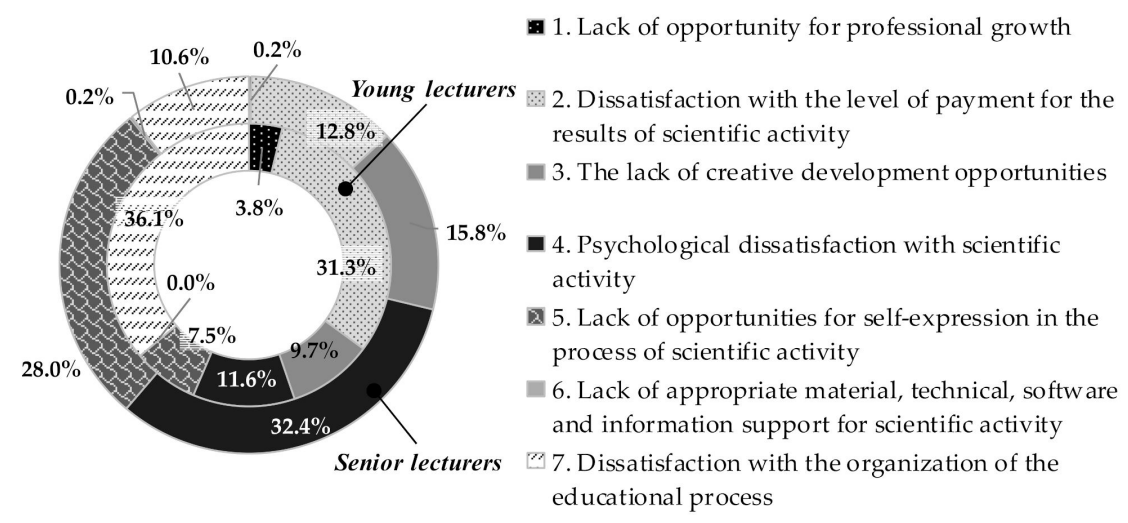

Figure 1. The distribution of the reasons for the decrease in the scientific activity productivity.

As the results of the research have shown, individual performance indicators of scientific activity of young and senior lecturers have an upward trend, and a decrease in the overall performance indicators of scientific activity for young lecturers is associated with staff outflow. At the same time, the tasks of the scientific activity of young and senior lecturers may differ, which affects the growth rate of individual performance indicators. The reasons for the shift of emphasis not in favor of scientific activity (in favor of organizational, methodical work, etc.) are the factors highlighted by the results of the study, which lead to a decrease in the potential values of the indicator of scientific activity efficiency. For senior lecturers, these are such factors as psychological dissatisfaction, lack of opportunity to express themselves and a lack of opportunity for creative development; for young teachers, these are 
dissatisfaction with the organization of the educational process and dissatisfaction with the level of payment for the results of scientific work.

\section{Discussion}

In the framework of this study, a macroeconomic analysis of productivity in Russian universities was carried out. To this end, an econometric model has been developed to evaluate the integral level of collective and individual lecturers' output. The novelty of the proposed model is in the method of calculating factor values (which allows combining indicators with different dimensions and also avoiding multicollinearity without the loss of information content) and significance factors (which takes into account the opinions of competent experts adjusted for the objective component, namely the statistical estimates, the influence of factors, and their informational content). All this is impossible to achieve with the summation of quantitative indicators and taxonomic analysis. This ensures the maximum accuracy of the results and takes into account the influence of all indicators, which is confirmed by the values of the correlation coefficients and the HO hypothesis. Based on the results obtained, it can be argued that the main hypothesis about the influence of age-related personal characteristics (factors) on scientific output is confirmed. In contrast to the results of other researchers [42,50], statistically significant differences were determined in the dynamics of the development of the indicators of the scientific activity of young and senior lecturers. The individual growth rate of the scientific productivity of young lecturers exceeds the growth rate of the senior lecturers' output. This revealed fact confirms the results of several studies [39-41]. However, it should be noted that in the framework of our research, we can state that this individual factor-age-does not affect the productivity of scientific activity very significantly but rather determines the strategy that must be chosen for successful scientific activity. This statement is confirmed by the fact that it is among young scientists and university professors that there is an outflow of personnel due to both leaving the profession and emigrating to foreign countries. In current conditions, this trend is pronounced for Russia. According to the World Bank, due to the massive outflow of scientists, Russia is losing about $\$ 2$ billion a year [51]. In Russia, a scientific career is not prestigious among young people. According to the Higher School of Economics, just over a third of citizens would like their children to become scientists. A low degree of aspiration toward the science professions among the Russian population becomes apparent with international comparisons; for example, in the United States and Israel, the vast majority of residents would support their children in choosing a scientific career [12].

The study gives priority to destructive factors that in current conditions hinder the development of the scientific activity output in Russian universities. It reveals that the main destructive factor for senior lecturers is psychological dissatisfaction with scientific activity (manifestations of an internal conflict between what is desired and what is achieved), including feeling a lack of the possibility of self-expression and creative development. For this category of teachers, the constraining factors are internal (motivators). Therefore, the factor of emotional burnout in senior scientists and lecturers deserves special attention in the personnel management system. According to the results of a study of young lecturers, the constraining factors for the development of scientific activity output are mainly external factors, like dissatisfaction with the educational process and the level of financing (salary, etc.). Unlike other systems of factors of scientific productivity $[43,44]$, this study puts forth a system of factors that considers the age factor and the division of lecturers into the categories of young and senior. This approach provides the opportunity to account for the most complete specifics of the personnel in the higher education system when developing and improving state policy for the development of science at the university level. The success of educational courses and a penchant for research should be considered when hiring graduates and teachers with experience in university positions. It is useful to take into account the described features of cooperation strategies when forming working groups and participating in large (including interdisciplinary and international) projects. The relationship between output and the nature of lecturers' and scientists' external experience (inbreeding and mobility) requires 
closer attention from Russian researchers, since the results described in the international literature are contradictory and depend on the characteristics of particular academic systems.

Based on the obtained results, it should be recommended that increasing the efficiency of the scientific productivity of Russian universities should be carried out within the framework of the concept of open innovation. The concept of open innovation defines the process of research and development as an open system [52-55]. Universities could attract new ideas and be present on the market with an innovative product not only through their own developments and creative ideas, but also through interaction with other business entities. Goal-setting directions of development of universities within the framework of the concept of open innovation should be determined by the main areas of activity $[2,3,54]$. In research activities, such tasks should be innovations in motivating employees for scientific activities and scientific cooperation with subjects of the external environment $[2,3,55]$. In the process of innovative development, the university can cooperate with other universities in the region, employers, business structures, professional communities and public organizations, government authorities, the media and others. Universities should aim to create integrated multi-entity communities for the joint research and development of innovations in order to achieve a single business goal of cooperation, as well as the business goals of individual community members. Access to resources on the basis of integrated interaction will significantly reduce the costs of creating an innovation and accelerate its implementation [3,52].

It should be noted that this study is based on a sample of respondents from Russian universities. Consequently, the results obtained can be considered in the conditions of the development of scientific activity output in the Russian higher education system. In addition, if we consider scientific organizations whose functional purpose is the implementation of scientific activity, then in universities, scientific work is one of the most important types of activity along with education. Consequently, the factors determining the efficiency of scientific activity in research organizations and in higher educational institutions have to vary. These aspects were not considered in the framework of this study due to the fundamental nature of the problem but will become one of the most important priorities of further research on scientific activity output.

\section{Conclusions}

This empirical study of the factors of the scientific activity output in Russian universities allowed the following conclusions. The age factor of lecturers and scientists has a significant impact on the level and development of their scientific activity output. Despite the fact that the level of scientific productivity among young lecturers is lower than that of senior ones, the individual growth rate of the young lecturers exceeded the growth rate among the senior ones. It was revealed that the reason for the decrease in the overall performance indicators of young lecturers is them leaving the profession or moving abroad. That is, the age factor of the lecturer/scientist does not affect the level of productivity but determines the strategy of scientific activity. Taking into account the age factor, this study shows that the determining factors of senior lecturer output are internal (motivators), whereas external factors form the basis for the development of the scientific activity output of young lecturers.

\subsection{Implication}

The developed model for assessing the productivity of scientific activity, as well as the deterministic regularities of the influence of factors of the productivity of scientific activity, it is advisable to take into account in the personnel policy of the higher education system in Russia for the constant monitoring of scientific detail. This will contribute to creating the necessary conditions for increasing scientific activity at universities, creating an institutional basis for significant motivation in the research area for applied activities focused on creating the innovative potential of the country's socio-economic development. 


\subsection{Limits and Future Research Topic}

A limitation of this study is that the proposed integral model for assessing the productivity of the scientific activity of teachers involves the use of the values of factors, calculated by the special software. Thus, to obtain an assessment of the productivity of the scientific activity of teachers, it is necessary to recalculate the values of the factors based on a new sample of observations. At the same time, the composition of factors and indicators of their significance remain unchanged for Russian universities due to the representativeness of the research sample. Based on this limitation, the priority for further research in this area is to build a universal model for assessing the productivity of scientific activity, which will use the absolute values of productivity indicators, rather than the values of factors.

Author Contributions: Conceptualization, M.V.; data curation, V.P. and O.D.; formal analysis, V.P.; investigation, T.V. and O.D.; methodology, T.V.; project administration, M.V.; resources, S.K. and N.N.; supervision, M.V.; writing-original draft, S.K. and N.N.; writing—review and editing, M.A., N.K. and I.E. All authors have read and agreed to the published version of the manuscript.

Funding: This research received no external funding.

Conflicts of Interest: The author declares no conflict of interest.

\section{References}

1. European Strategy Forum on Research Infrastructures Innovation Working Group. Innovation-Oriented Cooperation of Research Infrastructures; Dipartimento di Fisica-Università degli Studi di Milano: Milano, Italy, 2018; Volume 3.

2. Yun, J.J.; Won, D.; Park, K. Entrepreneurial cyclical dynamics of open innovation. J. Evol. Econ. 2018, 28, 1151-1174. [CrossRef]

3. Yun, J.; Liu, Z. Micro- and Macro-Dynamics of Open Innovation with a Quadruple-Helix Model. Sustainability 2019, 11, 3301. [CrossRef]

4. Tsvetkov, V.A.; Loginov, Y.L.; Raykov, A.N. Integrated networking of education with science and industry. Educ. Technol. Soc. 2016, 19, 389-398.

5. Organisation for Economic Co-operation and Development. Innovating Education and Educating for Innovation: The Power of Digital Technologies and Skills; Organisation for Economic Co-Operation and Development Publishing: Paris, France, 2016.

6. European University Association. A Contribution to the Horizon 2020 Mid-Term Review; European University Association: Brussels, Belgium, 2016.

7. President of Russia. On National Goals and Strategic Objectives of the Development of the Russian Federation up to 2024. Available online: http://kremlin.ru/acts/bank/43027 (accessed on 25 March 2020).

8. Lamanauskas, V.; Augienè, D. Development of Scientific Research Activity in University: A Position of the Experts. Procedia Soc. Behav. Sci. 2015, 167, 131-140. [CrossRef]

9. Analytical Center for the Government of the Russian Federation. Education Bulletin. Available online: http://ac.gov.ru/files/publication/a/18401.pdf (accessed on 25 March 2020).

10. Ratay, T.; Tarasenko, I. Scientific Staff: Downward Trend Continues. Institute for Statistical Studies and Economics of Knowledge, Higher School of Economics. Available online: https://issek.hse.ru/news/308115412. html (accessed on 25 March 2020).

11. Novye Izvestia. Russian Science Did Not Die, as It Moved Abroad. Available online: https://newizv.ru/news/ society/15-05-2019/rossiyskaya-nauka-ne-umerla-ona-pereehala-za-granitsu (accessed on 25 March 2020).

12. Vlasova, V.; Gokhberg, L.; Dyachenko, E.; Kuznetsova, I.; Kuznetsova, T.; Martynova, S.; Nefedova, A.; Ratay, T.; Roud, V.; Sagieva, G.; et al. Russian Science in Figures; National Research University Higher School of Economics: Moscow, Russia, 2018.

13. Brew, A.; Boud, D.; Namgung, S.U.; Lucas, L.; Crawford, K. Research productivity and academics'conceptions of research. High. Educ. 2016, 71, 681-697. [CrossRef]

14. Leišytė, L. New public management and research productivity-A precarious state of affairs of academic working The Netherlands. Stud. High. Educ. 2016, 41, 828-846. [CrossRef]

15. Angaiz, D. An Investigation of Teachers' Education Faculty Research Productivity in Public Sector Universities of Pakistan; Dowling College: New York, NY, USA, 2015. 
16. Nygaard, L.P. Publishing and perishing: An academic literacies framework for investigating research productivity. Stud. High. Educ. 2017, 42, 519-532. [CrossRef]

17. Creswell, J.W. Faculty Research Performance: Lessons from the Sciences and the Social Sciences; Association for the Study of Higher Education: Washington, DC, USA, 1985.

18. Bland, C.J.; Seaquist, E.; Pacala, J.T.; Center, B.; Finstad, D. One school's strategy to assess and improve the vitality of its faculty. Acad. Med. 2002, 77,368-376. [CrossRef]

19. Bland, C.J.; Center, B.A.; Finstad, D.; Risbey, K.R. A Theoretical, Practical, Predictive Model of Faculty and Department Research Productivity. Acad. Med. 2005, 80, 225-237. [CrossRef]

20. Fox, M.F. Publication Productivity among Scientists: A Critical Review. Soc. Stud. Sci. 1983, 13, $25-305$. [CrossRef]

21. Abramo, G.; D'Angelo, C.A. How do you define and measure research productivity? Scientometrics 2014, 101, 1129-1144. [CrossRef]

22. Lotka, A.J. The frequency distribution of scientific productivity. J. Wash. Acad. Sci. 1926, 16, 317-324.

23. Van Raan, A.F.J. Measuring science: Capita selecta of current main issues. In Handbook of Quantitative Science and Technology Research: The Use of Publication and Patent Statistics in Studies of SET Systems; Moed, H.F., Glänzel, W., Schmoch, U., Eds.; Kluwer: Dordrecht, The Netherlands, 2004; pp. 19-50.

24. Narin, F. Evaluative Bibliometrics: The Use of Publication and Citation Analysis in the Evaluation of Scientific Activity; National Science Foundation: Washington, DC, USA, 1976.

25. Godin, B. The Making of Science, Technology and Innovation Policy: Conceptual Frameworks as Narratives; Centre Urbanisation Culture Société: Quebec, QC, Canada, 2009.

26. Hicks, D.; Wouters, P.; Waltman, L.; de Rijcke, S. The Leiden Manifesto for research metrics. Nature 2015, 520, 429-431. [CrossRef] [PubMed]

27. Garfield, E. The evolution of the Science Citation Index. Int. Microbiol. 2007, 10, 65-69. [PubMed]

28. Académie Des Sciences. Du bon Usage de la Bibliométrie Pour L'évaluation Individuelle des Chercheurs. Available online: http://www.academie-sciences.fr/archivage_site/activite/rapport/avis170111_synthese.pdf (accessed on 10 December 2019).

29. Bernal, J.D. The Social Function of Science; The MIT Press: Cambridge, MA, USA, 1967.

30. Merton, R.K. The Matthew Effect in Science. Science 1968, 159, 56-63. [CrossRef]

31. Wildgaard, L.; Schneider, J.W.; Larsen, B. A review of the characteristics of 108 author-level bibliometric indicators. Scientometrics 2014, 101, 125-158. [CrossRef]

32. Van Norman, G.A.; Eisenkot, R. Technology Transfer: From the Research Bench to Commercialization: Part 2: The Commercialization Process. JACC Basic Transl. Sci. 2017, 2, 197-208. [CrossRef]

33. Yurevich, M.A. Methodological problems of evaluating the effectiveness of a researcher. Sci. Scientometr. Manag. 2014, 28-41.

34. Capone, V.; Joshanloo, M.; Sang-Ah Park, M. Burnout, depression, efficacy beliefs, and work-related variables among school teachers. Int. J. Educ. Res. 2019, 95, 97-108. [CrossRef]

35. Lundberg, C.; Gudmundson, A.; Andersson, T.D. Herzberg's Two-Factor Theory of work motivation tested empirically on seasonal workers in hospitality and tourism. Tour. Manag. 2009, 30, 890-899. [CrossRef]

36. Allison, P.D.; Stewart, J.A. Productivity Differences among Scientists: Evidence for Accumulative Advantage. Am. Sociol. Rev. 1974, 39, 596-606. [CrossRef]

37. Barinova, A.V. Problems of financing science. It Portal 2015, 1.

38. Mendeli, L.E.; Chernykh, S.I. Problems of financing domestic science, taking into account foreign experience. Econ. Sci. Educ. 2017, 89-103.

39. Nikulina, I.V.; Sanko, A.M. The motivation of the research activities of university teachers. Bull. Samara Sci. Cent. Russ. Acad. Sci. Soc. Humanit. Biomed. Sci. 2017, 19, 27-32.

40. Fursov, K.; Roshchina, Y.; Balmush, O. Factors of the effectiveness of scientific activity: Micro-level analysis. Foresight STI Gov. 2016, 10, 44-56. [CrossRef]

41. Bondareva, Y.P.; Sergeyev, S.A. Factors of professional adaptation of young university teachers. Probl. Pedagog. Psychol. 2016, 2, 258-266.

42. Strikhanov, M.; Trubetskov, D.; Koronovsky, A.; Sharaevsky, Y. Higher Education of Russia from the Standpoint of Nonlinear Dynamics; SPHERE: Moscow, Russia, 2018.

43. Reale, E.; DeFilippo, D.A.; Gómez, I.; Lepori, B.; Potì, B.; Primeri, E.; Probst, C.; Casado, E.S. New uses of the institutional databases of universities: Indicators of research activity. Res. Eval. 2011, 20, 47-60. [CrossRef] 
44. Chigisheva, O.P.; Bondarenko, A.V.; Soltovets, Y.M. Functional indicators of the productivity of research activities of young scientists. Balt. Humanit. J. 2017, 6, 429-433.

45. Presidium of the Presidential Council for Strategic Development and National Projects. National Project “Nauka". Available online: http://www.rshu.ru/university/science/documents/get_file.php?id=59 (accessed on 16 April 2020).

46. Ministry of Science and Higher Education of the Russian Federation, Order "On the Approval of Methods for Calculating Target and Additional Indicators for Monitoring the National Project "Science" and Federal Projects" Development of Scientific and Scientific-Industrial Cooperation", "Development of Advanced Infrastructure for Research and Development in the Russian Federation.". Available online: https://rosstat. gov.ru/metod/naz-proekt/met080003.pdf (accessed on 16 April 2020).

47. Ministry of Science and Higher Education of the Russian Federation. Order "On Approval of Performance Indicators of Federal Budgetary and Autonomous Educational Institutions of Higher Education Subordinate to the Ministry of Science and Higher Education of the Russian Federation, and the Work of Their Leaders, Based on the Results of Which Incentive Payments are Established to the Leaders of Such Institutions". Available online: http://docs.cntd.ru/document/564859636 (accessed on 16 April 2020).

48. Menke, W. Factor Analysis. In Geophysical Data Analysis, 4th ed.; Academic Press: New York, NY, USA, 2018; pp. 207-222.

49. Boyko, V.V. The Energy of Emotions in Communication: A Look at Yourself and Others; National Research University Higher School of Economics: Moscow, Russia, 1996.

50. Tretyakova, V.S. Study of burnout syndrome in a pedagogical environment. Vocat. Educ. Labor Mark. 2019, 2, 71-84.

51. World Bank Group. Modest Growth; Focus on Informality. Available online: http://pubdocs.worldbank.org/ en/115001560108403019/rer-41-english.pdf (accessed on 16 April 2020).

52. Chiaroni, D.; Chiesa, V.; Frattini, F. The Open Innovation Journey: How firms dynamically implement the emerging innovation management paradigm. Technovation 2011, 31, 34-43. [CrossRef]

53. Yun, J.H.; Zhao, X.; Jung, K.H.; Yigitcanlar, T. The Culture for Open Innovation Dynamics. Sustainability 2020, 12, 5076. [CrossRef]

54. Yun, J.H.J.; Kim, D.C.; Yan, M.-R. Open Innovation Engineering-Preliminary Study on New Entrance of Technology to Market. Electronics 2020, 9, 791. [CrossRef]

55. Chiaroni, D.; Chiesa, V.; Frattini, F. Unravelling the process from Closed to Open Innovation: Evidence from mature, asset-intensive industries. RD Manag. 2010, 40, 222-245. [CrossRef] 